\title{
Cell-Free DNA Results in Low Risk Pregnancy Screenings for Aneuploidies
}

\section{Dehghani AM*}

Department of Obstetrics and Gynecology Resident, Student Research Committee, AhvazJ undishapur University of Medical Sciences, Ahvaz, Iran

*Corresponding author: Azadeh Mohammadpour Dehghani, Department of Obstetrics and Gynecology Resident, Student Research Committee, Ahvaz J undishapur University of Medical Sciences, Ahvaz, Iran

Received: August 13, 2018; Accepted: September 20, 2018; Published: September 27, 2018

\begin{abstract}
Introduction: Chromosomal aneuploidies are a common type of chromosomal defect that may impose heavy burdens on society and families. The most common chromosomal aneuploidies among the embryos are trisomies 21,18 , and 13 . Prenatal screening and diagnosis are often used in prenatal care, and it seems to be a very useful tool for doctors and women to make informed decisions about the continuation of pregnancies involved with genetic diseases. Prenatal non-invasive tests using cell-free fetal DNA (cff DNA) are a method for testing trisomy in embryos using the peripheral blood sample of the pregnant mother. Considering the fact that most of the studies carried out on cell-free DNA have been in high-risk populations, this study attempted to examine the results of cell-free DNA in a population of low-risk aneuploidy pregnant women.
\end{abstract}

Materials and Methods: In this retrospective study, the study population was all pregnant women $(n=410)$, who underwent aneuploidy screening during the first or second trimester (with a low- risk result in Quad test) in 2015- 2016 and were at the risk of trisomies 13, 18, and 21 evaluated using cell-free DNA test.

Results: The mean age of pregnant women was 31.5 years and $92.0 \%$ of the subjects were naturally pregnant and only $8.1 \%$ had used Assisted Reproductive Techniques (ART). Of these, 5.9\% were fertilized by IVF and 2.2\% by IUI method. Results of cfDNA in all pregnant women were negative.

Conclusion: According to the results of this study, cfDNA testing results in all low risk pregnant women were negative and it is not recommended as a routine test in pregnant women reported as a low risk pregnancy in serum screening.

Keywords: Low-Risk Pregnancy; Aneuploidy Risk; Aneuploidy Screen; Cell-Free DNA

\section{Introduction}

Chromosomal aneuploidy is a common type of chromosomal defect that refers to the deviation from the normal human chromosome complement of 46. Fetal screening for chromosomal abnormalities is one of the mainstays of pregnancy care. Generally, women over the age of 35 are introduced for genetic counseling, while only $20 \%$ of Down's syndrome babies are born of women over the age of 30 years. With the advent of measuring the AFP maternal serum level in the mid-1980s, the pre-birth discriminant option for women younger than 35 years old was also created [1,2]. Common chromosomal aneuploidies are among the embryos of trisomy 21 (Down syndrome), trisomy 18 (Edward syndrome) and trisomy 13 (Patau syndrome). Trisomy 21 is the most common aneuploidy with an estimated prevalence of one in 700 births and its risk increases with maternal age. There is neither definitive treatment and nor effective treatment for these chromosomal aneuploidies. Therefore, identification of embryos with chromosomal aneuploidies is very important $[3,4]$. Prenatal noninvasive tests using cell-free fetal DNA (cff DNA) are a method for testing trisomy in embryos using a peripheral blood sample of a pregnant mother that have entered the market at present in 61 countries in Europe.

Fast measurements and non-invasive cff DNA can be used for many clinical applications, including gender identification, diagnosis of fetal aneuploidies, such as trisomies 13, 18 and 21, pregnancy complications, X-related diseases, cystic fibrosis, and several other single-gene diseases $[5,6]$. In singleton pregnancies, maternal bloodcff DNA testing can detect $99 \%$ of cases with trisomy $21,97 \%$ of cases with trisomy 18 , and $92 \%$ of cases with trisomy 13 with false positive rates of $<0.1,<0.2$ and $0.2 \%$, respectively [7-9].

\section{Materials and Methods}

This retrospective study includes all pregnant women who underwent the first or second trimester (Quad test) aneuploidy screening during the years 2015 and 2016, and were reported as having low risk, as well as risk assessment of trisomy 13, 18, and 21 using the cff DNA test for the reasons of mother's high age, parents' request, history of chromosomal disorder in the family, and so on. The subjects were at least 18 years of age and at the time of collecting blood sample, had a pregnancy with a gestational age of 10-13 weeks and 6 days or the second trimester (20-14 weeks) in the quad test. The 
gestational age is based on the CRL of the NT measurement time. Patients who were outside the window of gestational age did not have standard screening results, had known maternal aneuploidies, have been pregnant with the donor's ovule, or the empty gestational sack that was detected in ultrasound, were excluded from the study. All subjects underwent a standard screening (including PAPP serum measurements, Free or general $\beta$-hCG, and NT) or in the second trimester (UE3, Inhibin, Maternal AFP and $\beta$-hCG). Aneuploidy risk is estimated using a well-defined algorithm, including cfDNA chromosomal counts, cfDNA fetal fractions, and trisomy risk determined based on maternal and gestational age. A low-risk group is defined as pregnancies with a lower risk of less than 1 in 1500. If samples did not have lab quality control due to low cfDNA counts $(<4 \%)$ or the inability to measure fetal cfDNA fractions, high variation in cfDNA counts, or failure of the test, they were not included in the analysis.

\section{Results}

In this study, 410 low risk pregnant women were examined. The demographic information about the subjects studied is presented in the table 1 . The mean age of the women was 31.5 years. $75.4 \%$ of the women were in the first pregnancy. Furthermore, cfDNA results of all pregnant women were negative. In this study, the results of cfDNA in $100 \%$ of those who had negative results in the first trimester or quad test, were low risk.

\section{Discussion}

In this study, the mean age of pregnant women studied at the time of study was 31.5 years with a minimum of 18 years and a maximum of 40 years. Most of the subjects were aged 18 to 30 years old and $30.2 \%$ of women were over 35 years of age. The average weight of the subjects was $68.79 \mathrm{~kg}$, with a minimum of $43 \mathrm{~kg}$ and a maximum of $115 \mathrm{~kg}$, and the mean height of the subjects was $161.39 \mathrm{~cm}$, with a minimum of $141 \mathrm{~cm}$ and a maximum of $186 \mathrm{~cm}$. The average BMI of the subjects was $26.40 \mathrm{~kg} / \mathrm{m}^{2}$ with a minimum of $16.53 \mathrm{~kg} / \mathrm{m}^{2}$ and a maximum of $40.63 \mathrm{~kg} / \mathrm{m}^{2}$. Furthermore, $1.2 \%$ of the patients were underweight, and $1.0 \%$ of the patients had severe obesity.

In the study conducted by Radoi et al. [7] on Romanian women, the mean age of the studied women was 36.8 years with a minimum of 24 and a maximum of 44 years. The average weight of these people was $64.9 \mathrm{~kg}$ with a minimum of 45 and a maximum of $114 \mathrm{~kg}$. In the study conducted by Norton et al., The mean age of the subjects was 31 years and $73.6 \%$ were younger than 35 years old. In the study conducted by Norton et al. [10], the average age was 30.7 years old, with a minimum of 18 and a maximum of 48 years. The average weight of mothers was $65.8 \mathrm{~kg}$ with a minimum of 31.8 and a maximum of $172.4 \mathrm{~kg}$. In a study of pregnant women in Italy, conducted by Persica et al. [11], the average age of women examined was 36 years, with a minimum of 20 and a maximum of 46 years. The mean age of women in this study was lower than the mean age of women in the studies conducted in Romania and Italy and was higher than the mean age in studies conducted by Norton and Wei-Lin Ke.

In this study, the percentage of women over 35 years was higher than in other studies, which highlighted the percentage of women above 35 years of age. Considering that the increase in the age of mothers is also a risk factor for pregnancy with a fetus with a
Table 1: Demographic data of pregnant women studied.

\begin{tabular}{|c|c|c|}
\hline \multicolumn{2}{|c|}{ Variable } & Number (percent) \\
\hline \multirow{3}{*}{ Mother's age } & 18 to 30 & $154(37.6 \%)$ \\
\hline & 31 to 35 & $132(32.2 \%)$ \\
\hline & Above 35 & $124(30.2 \%)$ \\
\hline \multirow{6}{*}{ Pregnancy frequency } & 1 & $175(42.7 \%)$ \\
\hline & 2 & $134(32.7 \%)$ \\
\hline & 3 & $68(16.6 \%)$ \\
\hline & 4 & $22(5.4 \%)$ \\
\hline & 5 & $9(2.2 \%)$ \\
\hline & 6 & $2(0.5 \%)$ \\
\hline \multirow{4}{*}{ Delivery frequency } & 0 & $201(49.0 \%)$ \\
\hline & 1 & $151(36.8 \%)$ \\
\hline & 2 & $51(12.4 \%)$ \\
\hline & 3 & $7(1.7 \%)$ \\
\hline \multirow{5}{*}{ Abortion frequency } & 0 & 325 (79.3) \\
\hline & 1 & $64(15.6 \%)$ \\
\hline & 2 & $16(3.9 \%)$ \\
\hline & 3 & $2(0.5 \%)$ \\
\hline & 4 & $3(0.7 \%)$ \\
\hline \multirow{3}{*}{ Pregnancy method } & Normal & $377(92.0 \%)$ \\
\hline & IVF & $24(5.9 \%)$ \\
\hline & IUI & $9(2.2 \%)$ \\
\hline \multirow{2}{*}{ Number of fetal twins } & 1 & $401(97.8 \%)$ \\
\hline & 2 & $9(2.2 \%)$ \\
\hline \multirow{6}{*}{ BMI } & Lack of weight (less than 18.5) & $5(1.2 \%)$ \\
\hline & Normal (18.5 to 24.9 ) & $167(40.7 \%)$ \\
\hline & Overweight (25 to 29.9 ) & $153(37.3 \%)$ \\
\hline & Obesity grade 1 (30 to 34.9 ) & $69(16.8)$ \\
\hline & Obesity grade 2 (35 to 39.9 ) & $12(2.9 \%)$ \\
\hline & Excessive obesity (over 40 ) & $4(1.0 \%)$ \\
\hline
\end{tabular}

Table 2: Results of cfDNA by the results of first trimester screening and quad test.

\begin{tabular}{|c|c|c|c|}
\hline \multirow{2}{*}{ Routine screening tests } & \multirow{2}{*}{ Results } & \multicolumn{2}{|c|}{ Results of cfDNA } \\
\cline { 3 - 4 } & & Low risk & High risk \\
\hline First trimester & Negative & 238 & 0 \\
\hline Quad test & Negative & 172 & 0 \\
\hline
\end{tabular}

chromosomal disorder, this happens with mothers over the age of 35 years, and in these cases, it is necessary to carry out more screening tests during pregnancy, most women in this study and other studies are women older than 35 years of age.

The mean weight of the women examined in this study is greater than in studies conducted in Romania and Norton. Given that maternal weight gain increases the probability that the exact results of the cfDNA test are not diagnostic, as well as the results of investigations done in various studies in cases where the cfDNA test is not diagnostic, have shown that the weight of these subjects 
was greater than that of the women who have been tested using a diagnostic cfDNA test. According to the results of previous studies, more precision in this screening test is recommended in high-weight women.

On average, frequency of pregnancy of the women was 1.93 with at least 1 time and up to 6 times of pregnancy, and only $24.6 \%$ of women had experienced more than 2 pregnancy periods. On average, delivery frequency in the subjects was 0.67 times, with a minimum of 0 and no more than 3 times. $49 \%$ of the subjects were nulliparous, and $20.7 \%$ of the subjects reported at least one incidence of abortion.

About $92.0 \%$ of the subjects were naturally pregnant and only 8.1\% had used Assisted Reproductive Techniques (ART), of which $5.9 \%$ were fertilized by IVF and $2.2 \%$ by IUI method. $97.8 \%$ of the subjects had singleton pregnancies and only $2.2 \%$ had a twin pregnancy. In the study conducted by Norton, 3.0\% of pregnancies were by ART. This prevalence of using ART in the present study has been due to the unwillingness to carry out screening by the families who were naturally pregnant.

This study was performed on 410 pregnant women, 100\% of whom in routine screenings were reported as low risk in the first or second trimester. In the study of women in Romania, conducted by Radoi et al., $13.93 \%$ of the subjects were at high risk for trisomy 21 in the first or second trimester screenings, and the rest (86.07\%) were low risk due to their high maternal age or signs of chromosomal disorder in sonography or due to doing the cfDNA test for them on their own request. In the study conducted by Norton et al., $5 \%$ of the subjects were reported as high risk in the first or second trimester screenings, and 95\% were low risk in the first or second trimester screenings. In the study conducted by Persico et al., all women were reported as high risk in the first or second trimester screenings.

In this study, negative cfDNA results were reported in $100 \%$ of pregnant women. In the study conducted by Radoi et al., cfDNA results of $94.2 \%$ of patients was negative and $2.48 \%$ of patients had positive cfDNA reports that were confirmed in amniocentesis and post-abortion examinations. In $3.48 \%$ of patients, cfDNA was not reported as a result of which the weight of mothers was higher than others [5]. In the study conducted by Norton et al., the diagnostic power of cfDNA testing in trisomies 21,18 , and 13 was $99.2 \%, 96.3 \%$, and $91.0 \%$, respectively (48). In the study conducted by Wei-Lin Ke et al., 17 pregnancies were reported in the cfDNA diagnostic tests for trisomy 21, and also 6 pregnancies were reported for trisomy 18 , and 1 pregnancy for high-risk trisomy 13 , which $100 \%$ of these subjects were confirmed using karyotype analysis after birth or abortion. In addition, in the 2316 pregnancies, the results of the lower risk cfDNA testing were reported, which were confirmed in the upcoming evaluations [9]. In a study of low-risk individuals for trisomy 21, conducted by Norton et al., cfDNA test diagnosed 100\% of cases of non-infected pregnancies, and also $100 \%$ of the affected cases, and sensitivity, specificity, positive predictive value and negative predictive value calculated of the test for low risk subjects in trisomy 21 diagnosis was reported to be $100 \%, 99.9 \%, 50 \%$, and $100 \%$, respectively. In the study conducted by Persico et al., CfDNA results were positive in $97.2 \%$ of pregnancies with trisomy 21 and in $100 \%$ of cases, trisomy 18 and 13 were positive. Also, in 100\% of low-risk pregnancies, the reported cfDNA test results were negative [8]. The results of this study were consistent with earlier studies that reported the results for low risk pregnant women and also, in all pregnant women who were reported as low risk in the first or second trimester screenings, the reported cfDNA test results were negative.

\section{References}

1. Driscoll DA, Gross S. Prenatal screening for aneuploidy. New England Journal of Medicine. 2009; 360: 2556-2562.

2. Verweij E, Van Den Oever J, De Boer M, Boon E, Oepkes D. Diagnostic accuracy of noninvasive detection of fetal trisomy 21 in maternal blood: a systematic review. Fetal diagnosis and therapy. 2012; 31: 81-86.

3. Stein W, Müller S, Gutensohn K, Emons G, Legler T. Cell-free fetal DNA and adverse outcome in low risk pregnancies. European Journal of Obstetrics and Gynecology and Reproductive Biology. 2013; 166: 10-13.

4. Gil MdM, Quezada MS, Bregant B, Syngelaki A, Nicolaides KH. Cell-free DNA analysis for trisomy risk assessment in first-trimester twin pregnancies. Fetal diagnosis and therapy. 2014; 35: 204-211.

5. Costa CA. Noninvasive prenatal screening for chromosomal abnormalities using circulating cell-free fetal DNA in maternal plasma: Current applications, limitations and prospects. Egyptian Journal of Medical Human Genetics. 2017; 18: 1-7.

6. Taylor-Phillips S, Freeman K, Geppert J, Agbebiyi A, Uthman OA, Madan $\mathrm{J}$, et al. Accuracy of non-invasive prenatal testing using cell-free DNA for detection of Down, Edwards and Patau syndromes: a systematic review and meta-analysis. BMJ open. 2016; 6: e010002.

7. Radoi VE, Bohiltea CL, Bohiltea RE, Albu DN. Cell free fetal DNA testing in maternal blood of Romanian pregnant women. Iranian journal of reproductive medicine. 2015; 13: 623-626.

8. Hudecova I, Sahota D, Heung MM, Jin Y, Lee WS, Leung TY, et al. Maternal plasma fetal DNA fractions in pregnancies with low and high risks for fetal chromosomal aneuploidies. PloS one. 2014; 9: e88484.

9. Norton ME, Jacobsson B, Swamy GK, Laurent LC, Ranzini AC, Brar H, et al. Cell-free DNA analysis for noninvasive examination of trisomy. New England Journal of Medicine. 2015; 372: 1589-1597.

10. Norton ME, Baer RJ, Wapner RJ, Kuppermann M, Jelliffe-Pawlowski LL, Currier RJ, et al. Cell-free DNA vs sequential screening for the detection of fetal chromosomal abnormalities. American Journal of Obstetrics \& Gynecology. 2016; 214: 727. e1 - e6.

11. Persico N, Boito S, Ischia B, Cordisco A, De Robertis V, Fabietti I, et al. Cell-free DNA testing in the maternal blood in high-risk pregnancies after firsttrimester combined screening. Prenatal diagnosis. 2016; 36: 232-236.
Austin J Obstet Gynecol - Volume 5 Issue 7 - 2018 Submit your Manuscript | www.austinpublishinggroup.com Dehghani. (C) All rights are reserved
Citation: Dehghani AM. Cell-Free DNA Results in Low Risk Pregnancy Screenings for Aneuploidies. Austin J Obstet Gynecol. 2018; 5(7): 1122. 